\title{
On Bicomplex Nets and their Confinements
}

\author{
Rajiv K. Srivastava*, S. Singh \\ Department of Mathematics, Institute of Basic Science, Khandari Campus, Dr. B. R. Ambedkar University, Agra - 282 002, India
}

\begin{abstract}
We have initiated the study of nets with bicomplex entries. Due to the multi dimensionality of the bicomplex space there arise different types of tendencies called confinements. The bicomplex space equipped with real order topology as well as idempotent order topology exhibits interesting and challenging behaviour of nets. Different types of confinements have been characterized in terms of convergence of the component nets. In the final section, certain relations between bicomplex nets and their projection nets have been derived.
\end{abstract}

Keywords Bicomplex Numbers, Order Topology, Bicomplex Net, Real Confinement, Idempotent Confinement, Projection Net

\section{Introduction}

The symbols $\mathrm{C}_{0}, \mathrm{C}_{1}$ and $\mathrm{C}_{2}$ denote sets of real numbers, complex numbers and bicomplex numbers, respectively.

A bicomplex number is defined as (cf.[1,2])

$$
\xi=x_{1}+i_{1} x_{2}+i_{2} x_{3}+i_{1} i_{2} x_{4},
$$

where $x_{p} \in C_{0}, 1 \leq p \leq 4, \quad z_{1}, z_{2} \in C_{1}, i_{1}^{2}=i_{2}^{2}=-1$ and $\mathrm{i}_{1} \mathrm{i}_{2}=\mathrm{i}_{2} \mathrm{i}_{1}$.

With usual binary compositions, $\mathrm{C}_{2}$ becomes a commutative algebra with identity. Besides the additive and multiplicative identities 0 and 1 , there exist exactly two non-trivial idempotent elements denoted by $e_{1}$ and $e_{2}$ defined as $\mathrm{e}_{1}=\left(1+\mathrm{i}_{1} \mathrm{i}_{2}\right) / 2$ and $\mathrm{e}_{2}=\left(1-\mathrm{i}_{1} \mathrm{i}_{2}\right) / 2$. Note that $\mathrm{e}_{1}+\mathrm{e}_{2}=1$ and $\mathrm{e}_{1} \cdot \mathrm{e}_{2}=0$.

A bicomplex number $\xi=z_{1}+i_{2} z_{2}$ can be uniquely expressed as a complex combination of $\mathrm{e}_{1}$ and $\mathrm{e}_{2}$ as (cf. [3])

$$
\begin{gathered}
\xi=z_{1}+i_{2} z_{2} \\
=\left(z_{1}-i_{1} z_{2}\right) e_{1}+\left(z_{1}+i_{1} z_{2}\right) e_{2} \\
={ }^{1} \xi e_{1}+{ }^{2} \xi e_{2},
\end{gathered}
$$

where ${ }^{1} \xi=z_{1}-i_{1} z_{2}$ and ${ }^{2} \xi=z_{1}+i_{1} z_{2}$.

The complex coefficients ${ }^{1} \xi$ and ${ }^{2} \xi$ are called the idempotent components and the combination ${ }^{1} \mathrm{e}_{1}+{ }^{2} \xi \mathrm{e}_{2}$ is known as idempotent representation of bicomplex number $\xi$.

The auxiliary complex spaces $\mathrm{A}_{1}$ and $\mathrm{A}_{2}$ are defined

* Corresponding author:

ssukhdev1209@yahoo.com ( S. Singh )

Published online at http://journal.sapub.org/ajms

Copyright (C) 2011 Scientific \& Academic Publishing. All Rights Reserved as follows:

$$
\begin{gathered}
\mathrm{A}_{1}=\left\{\mathrm{z}_{1}-\mathrm{i}_{1} \mathrm{z}_{2} ; \mathrm{z}_{1}, \mathrm{z}_{2} \in \mathrm{C}_{1}\right\}=\left\{{ }^{1} \xi: \xi \in \mathrm{C}_{2}\right\} \\
\text { and } \mathrm{A}_{2}=\left\{\mathrm{z}_{1}+\mathrm{i}_{1} \mathrm{z}_{2} ; \mathrm{z}_{1}, \mathrm{z}_{2} \in \mathrm{C}_{1}\right\}=\left\{2 \xi: \xi \in \mathrm{C}_{2}\right\}
\end{gathered}
$$

The idempotent representation

$$
\left(\mathrm{z}_{1}-\mathrm{i}_{1} \mathrm{z}_{2}\right) \mathrm{e}_{1}+\left(\mathrm{z}_{1}+\mathrm{i}_{1} \mathrm{z}_{2}\right) \mathrm{e}_{2}={ }^{1} \xi \mathrm{e}_{1}+{ }^{2} \xi \mathrm{e}_{2}
$$

associates with each point $\xi=z_{1}+i_{2} z_{2}$ in $C_{2}$, the points ${ }^{1} \xi=z_{1}-i_{1} z_{2}$ and ${ }^{2} \xi=z_{1}+i_{1} z_{2}$ in $A_{1}$ and $A_{2}$, respectively and to each pair of points $(\mathrm{z}, \mathrm{w}) \in \mathrm{A}_{1} \times \mathrm{A}_{2}$, there corresponds a unique bicomplex point $\xi=\mathrm{ze}_{1}+\mathrm{we}_{2}$. Some updated details of the theory of Bicomplex Numbers can be found in $[5,6]$.

\section{Order Topologies on $\mathbf{C}_{2}$}

Srivastava[3] initiated the topological study of $\mathrm{C}_{2}$. He defined three topologies on $\mathrm{C}_{2}$, viz., norm topology $\tau_{1}$, complex topology $\tau_{2}$ and idempotent topology $\tau_{3}$ and has proved some results on these topological structures.

Throughout, $<$ denotes the ordering of real numbers and $\prec$ denotes the dictionary ordering of the complex numbers. Denote by $\prec_{R}$, the dictionary ordering of bicomplex numbers expressed in the real component form. The order topologies induced by this ordering will be called as Real Order Topology (cf.[4]), denoted by $\tau_{4}$ and is generated by the basis comprising of the members of the following families of subsets of $\mathrm{C}_{2}$ :

$$
\begin{aligned}
& J_{1}=\left\{\left(\begin{array}{l}
x_{1}+i_{1} x_{2}+i_{2} x_{3}+i_{1} i_{2} x_{4}, y_{1} \\
+i_{1} y_{2}+i_{2} y_{3}+i_{1} i_{2} y_{4}
\end{array}\right)_{R}: x_{1}<y_{1}\right\} \\
& \left.J_{2}=\left\{\begin{array}{l}
a+i_{1} x_{2}+i_{2} x_{3}+i_{1} i_{2} x_{4}, a+ \\
i_{1} y_{2}+i_{2} y_{3}+i_{1} i_{2} y_{4}
\end{array}\right)_{R}: x_{2}<y_{2}\right\}
\end{aligned}
$$




$$
\begin{aligned}
& J_{3}=\left\{\left(\begin{array}{l}
a+i_{1} b+i_{2} x_{3}+i_{1} i_{2} x_{4}, a \\
+i_{1} b+i_{2} y_{3}+i_{1} i_{2} y_{4}
\end{array}\right)_{R}: x_{3}<y_{3}\right\} \\
& J_{4}=\left\{\left(\begin{array}{l}
a+i_{1} b+i_{2} c+i_{1} i_{2} x_{4}, a \\
+i_{1} b+i_{2} c+i_{1} i_{2} y_{4}
\end{array}\right)_{R}: x_{4}<y_{4}\right\},
\end{aligned}
$$

the set $(\xi, \eta)_{R}$ denoting the open interval with respect to the ordering $\prec_{\mathrm{R}}$.

Throughout the discussion, we shall consider some special types of subsets of the bicomplex space $\mathrm{C}_{2}$, equipped with real order topology.

A set of the type

$\left\{\xi: \xi=x_{1}+i_{1} x_{2}+i_{2} x_{3}+i_{1} i_{2} x_{4}: a<x_{1}\right.$ and $\left.x_{1}<b\right\}$ is called an open space segment.

A set of the type $\left\{\xi: \xi=a+i_{1} x_{2}+i_{2} x_{3}+i_{1} i_{2} x_{4}\right\}$ is called a frame and is denoted as $\left(x_{1}=a\right)$. A set of the type $\{\xi: \xi=$ $a+i_{1} x_{2}+i_{2} x_{3}+i_{1} i_{2} x_{4} ; b<x_{2}$ and $\left.x_{2}<c\right\}$ is called an open frame segment.

A set of the type $\left\{\xi: \xi=a+i_{1} b+i_{2} x_{3}+i_{1} i_{2} x_{4}\right\}$ is called as plane and is denoted as $\left(x_{1}=a, x_{2}=b\right)$. A set of the type $\left\{\xi: \xi=a+i_{1} b+i_{2} x_{3}+i_{1} i_{2} x_{4} ; c<x_{3}\right.$ and $\left.x_{3}<d\right\}$ is called an open plane segment.

A set of the type $\left\{\xi: \xi=a+i_{1} b+i_{2} c+i_{1} i_{2} x_{4}\right\}$ is called as a line and is denoted as $\left(\mathrm{x}_{1}=\mathrm{a}, \mathrm{x}_{2}=\mathrm{b}, \mathrm{x}_{3}=\mathrm{c}\right)$. A set of the type $\left\{\xi: \xi=a+i_{1} b+i_{2} c+i_{1} i_{2} x_{4} ; d<x_{4}\right.$ and $\left.x_{4}<e\right\}$ is called an open line segment.

Note that $J_{1}$ is a family of open space segments, $J_{2}$ is a family of open frame segments, $J_{3}$ is a family of open plane segments and $\mathrm{J}_{4}$ is a family of open line segments.

Further, we shall consider some special types of subsets of the bicomplex space $\mathrm{C}_{2}$ equipped with the idempotent order topology, (cf.[4]).

Denote by $\prec_{\text {ID }}$, the dictionary ordering of the bicomplex numbers expressed in the idempotent form. The order topology induced by this ordering is called as Idempotent Order Topology (cf.[4]). Hence, idempotent order topology, $\tau_{6}$ is generated by the basis $B_{6}$ comprising of members of the following families of subsets of $\mathrm{C}_{2}$ :

$$
\begin{aligned}
\mathrm{L}_{1} & =\left\{\left({ }^{1} \xi \mathrm{e}_{1}+{ }^{2} \xi \mathrm{e}_{2},{ }^{1} \eta \mathrm{e}_{1}+{ }^{2} \eta \mathrm{e}_{2}\right)_{\mathrm{ID}}:{ }^{1} \xi \prec{ }^{1} \eta\right\} \\
\mathrm{L}_{2} & =\left\{\left({ }^{1} \xi \mathrm{e}_{1}+{ }^{2} \xi \mathrm{e}_{2},{ }^{1} \xi \mathrm{e}_{1}+{ }^{2} \eta \mathrm{e}_{2}\right)_{\mathrm{ID}}:{ }^{2} \xi \prec{ }^{2} \eta\right\},
\end{aligned}
$$

the set $(\xi, \eta)_{\mathrm{ID}}$ denoting the open interval with respect to the ordering $\prec_{\mathrm{ID}}$.

A set of the type $\left\{\xi: a<\operatorname{Re}^{1} \xi<b\right\}$ is called an open ID - space segment.

A set of the type $\left\{\xi: \operatorname{Re}^{1} \xi=\mathrm{a}\right\}$ is called an ID - frame and is denoted as $\left(\operatorname{Re}^{1} \xi=\mathrm{a}\right)$. A set of the type $\left\{\xi: \operatorname{Re}^{1} \xi=\mathrm{a}, \mathrm{b}<\operatorname{Im}^{1} \xi<\mathrm{c}\right\}$ is called an open ID frame segment.

A set of the type $\left\{\xi: \operatorname{Re}^{1} \xi=a, \operatorname{Im}^{1} \xi=b\right\}$ is called as an ID - plane and is denoted as $\left(\operatorname{Re}^{1} \xi=\mathrm{a}, \operatorname{Im}^{1} \xi=\mathrm{b}\right)$.

A set of the type $\left\{\xi: \operatorname{Re}^{1} \xi=\mathrm{a}, \operatorname{Im}^{1} \xi=\mathrm{b}, \mathrm{c}<\operatorname{Re}^{2} \xi<\mathrm{d}\right\}$ is called an open ID - plane segment. A set of the type $\left\{\xi: \operatorname{Re}^{1} \xi=\mathrm{a}, \operatorname{Im}^{1} \xi=\mathrm{b}, \operatorname{Re}^{2} \xi=\mathrm{c}\right\}$ is called an ID - line and is denoted as $\left(\operatorname{Re}^{1} \xi=\mathrm{a}, \operatorname{Im}^{1} \xi=\mathrm{b}, \operatorname{Re}^{2} \xi=\mathrm{c}\right)$.

A set of the type

$\left\{\xi: \operatorname{Re}^{1} \xi=\mathrm{a}, \operatorname{Im}^{1} \xi=\mathrm{b}, \operatorname{Re}^{1} \xi=\mathrm{c}, \mathrm{d}<\operatorname{Im}^{2} \xi<\mathrm{e}\right\}$

is called an open ID - line segment.

\subsection{Remark}

Note that, $\mathrm{L}_{1}$ and $\mathrm{L}_{2}$ can also be described as $\mathrm{L}_{1}=\mathrm{N}_{1} \cup \mathrm{N}_{2}$ and $\mathrm{L}_{2}=\mathrm{N}_{3} \cup \mathrm{N}_{4}$, where

$$
\begin{aligned}
& \mathrm{N}_{1}=\left\{\left({ }^{1} \xi \mathrm{e}_{1}+{ }^{2} \xi \mathrm{e}_{2},{ }^{1} \eta \mathrm{e}_{1}+{ }^{2} \eta \mathrm{e}_{2}\right)_{\mathrm{ID}}: \operatorname{Re}^{1} \xi<\operatorname{Re}^{1} \eta\right\} \\
& \mathrm{N}_{2}=\left\{\begin{array}{l}
\left({ }^{1} \xi \mathrm{e}_{1}+{ }^{2} \xi \mathrm{e}_{2},{ }^{1} \eta \mathrm{e}_{1}+{ }^{2} \eta \mathrm{e}_{2}\right)_{\mathrm{ID}} \\
: \operatorname{Re}^{1} \xi=\operatorname{Re}^{1} \eta, \operatorname{Im}^{1} \xi<\operatorname{Im}{ }^{1} \eta
\end{array}\right\} \\
& \mathrm{N}_{3}=\left\{\left({ }^{1} \xi \mathrm{e}_{1}+{ }^{2} \xi \mathrm{e}_{2},{ }^{1} \xi \mathrm{e}_{1}+{ }^{2} \eta \mathrm{e}_{2}\right)_{\mathrm{ID}}: \operatorname{Re}^{2} \xi<\operatorname{Re}^{2} \eta\right\} \\
& \mathrm{N}_{4}=\left\{\begin{array}{l}
\left({ }^{1} \xi \mathrm{e}_{1}+{ }^{2} \xi \mathrm{e}_{2},{ }^{1} \xi \mathrm{e}_{1}+{ }^{2} \eta \mathrm{e}_{2}\right)_{\mathrm{ID}} \\
: \operatorname{Re}^{2} \xi=\operatorname{Re}^{2} \eta, \operatorname{Im}^{2} \xi<\operatorname{Im}^{2} \eta
\end{array}\right\}
\end{aligned}
$$

In other words,

$$
\mathrm{B}_{4}=\bigcup_{\mathrm{p}=1}^{4} \mathrm{~J}_{\mathrm{p}} \text { and } \mathrm{B}_{6}=\bigcup_{\mathrm{p}=1}^{2} \mathrm{~L}_{\mathrm{p}}=\bigcup_{\mathrm{p}=1}^{4} \mathrm{~N}_{\mathrm{p}} \text {. }
$$

\subsection{Remark}

The geometry of the Cartesian idempotent set determined by $A_{1}$ and $A_{2}$, i.e., $A_{1} \times A_{2}$ is entirely different from the geometry of Cartesian set determined by $\mathrm{C}_{1}$ and $\mathrm{C}_{1}$, i.e., $\mathrm{C}_{1} \times_{\mathrm{c}} \mathrm{C}_{1}$ (for definitions see[3]). Obviously, the members of the families $\mathrm{N}_{1}, \mathrm{~N}_{2}, \mathrm{~N}_{3}$ and $\mathrm{N}_{4}$ are open ID - space segments, open ID - frame segments, open ID - plane segments and open ID - line segments, respectively.

\section{Confinements of Bicomplex Nets in the Real Order Topology}

\subsection{Static and Eventually Static Bicomplex Net}

Let $\mathrm{D}$ be an arbitrary directed set. Then a bicomplex net can be defined as $\Phi: \mathrm{D} \rightarrow \mathrm{C}_{2}$ such that $\forall \alpha \in \mathrm{D}$

$$
\begin{aligned}
\Phi(\alpha) & =\xi_{\alpha}=\mathrm{x}_{1 \alpha}+\mathrm{i}_{1} \mathrm{x}_{2 \alpha}+\mathrm{i}_{2} \mathrm{x}_{3 \alpha}+\mathrm{i}_{1} \mathrm{i}_{2} \mathrm{x}_{4 \alpha} \\
& =\mathrm{z}_{1 \alpha}+\mathrm{i}_{2} \mathrm{z}_{2 \alpha} \\
& ={ }^{1} \xi_{\alpha} \mathrm{e}_{1}+{ }^{2} \xi_{\alpha} \mathrm{e}_{2}
\end{aligned}
$$

Further, a bicomplex net $\left\{\xi_{\alpha}\right\}$ is said to be static on $\xi$ if $\xi_{\alpha}=\xi, \forall \alpha \in \mathrm{D}$. It is said to be eventually static on $\xi$ if there exists $\beta \in \mathrm{D}$ such that $\xi_{\alpha}=\xi, \forall \alpha \geq \beta$. 


\subsection{Real Frame Confinement (RF Confinement)}

A bicomplex net

$$
\left\{\xi_{\alpha}\right\}=\left\{x_{1 \alpha}+i_{1} x_{2 \alpha}+i_{2} x_{3 \alpha}+i_{1} i_{2} x_{4 \alpha}\right\}
$$

is said to be Real Frame confined (in short, RF confined) to the frame $\left(\mathrm{x}_{1}=\mathrm{a}\right)$, if it eventually in every member of the family $\mathrm{J}_{1}$ (of open space segments) containing the frame $\left(\mathrm{x}_{1}=\mathrm{a}\right)$.

\subsection{Real Plane Confinement (RP Confinement)}

A bicomplex net

$$
\left\{\xi_{\alpha}\right\}=\left\{x_{1 \alpha}+i_{1} x_{2 \alpha}+i_{2} x_{3 \alpha}+i_{1} i_{2} x_{4 \alpha}\right\}
$$

is said to be Real Plane confined (in short, RP confined) to the plane $\left(\mathrm{x}_{1}=\mathrm{a}, \mathrm{x}_{2}=\mathrm{b}\right)$, if it is eventually in every member of the family $J_{2}$ (of open frame segments) containing the plane $\left(\mathrm{x}_{1}=\mathrm{a}, \mathrm{x}_{2}=\mathrm{b}\right)$.

\subsection{Real Line Confinement (RL Confinement)}

A bicomplex net

$$
\left\{\xi_{\alpha}\right\}=\left\{\mathrm{x}_{1 \alpha}+\mathrm{i}_{1} \mathrm{x}_{2 \alpha}+\mathrm{i}_{2} \mathrm{x}_{3 \alpha}+\mathrm{i}_{1} \mathrm{i}_{2} \mathrm{x}_{4 \alpha}\right\}
$$

is said to be Real Line confined (in short, RL confined) to the line $\left(x_{1}=a, x_{2}=b, x_{3}=c\right)$, if it is eventually in every member of the family $J_{3}$ (of open plane segments) containing the line $\left(x_{1}=a, x_{2}=b, x_{3}=c\right)$.

\subsection{Real Point Confinement ( $R$ - Point Confinement)}

\section{A bicomplex net}

$$
\left\{\xi_{\alpha}\right\}=\left\{x_{1 \alpha}+i_{1} x_{2 \alpha}+i_{2} x_{3 \alpha}+i_{1} i_{2} x_{4 \alpha}\right\}
$$

is said to be Real Point confined (in short, $\mathrm{R}$ - Point confined) to the bicomplex point $\xi=\mathrm{a}+\mathrm{i}_{1} \mathrm{~b}+\mathrm{i}_{2} \mathrm{c}+\mathrm{i}_{1} \mathrm{i}_{2} \mathrm{~d}$, if it is eventually in every member of the family $\mathrm{J}_{4}$ (of open line segments) containing the point $\xi$.

\subsection{Remark}

Note that if a bicomplex net $\left\{\xi_{\alpha}\right\}$ is RF confined to the frame $\left(x_{1}=a\right)$, it will not be eventually in any member of the family $\mathrm{J}_{2}$ (and therefore will not be RP confined to any plane) unless $\left\{\mathrm{x}_{1 \alpha}\right\}$ is eventually static on ' $\mathrm{a}$ ' (and in this case, $\left\{\xi_{\alpha}\right\}$ will be RP confined to the plane $\left(\mathrm{x}_{1}=\mathrm{a}, \mathrm{x}_{2}=\mathrm{b}\right)$ provided that $\left.\left\{\mathrm{x}_{2 \alpha}\right\} \rightarrow \mathrm{b}\right)$. Similar cases will arise with the other types of bicomplex nets in the real form.

\subsection{Remark}

The $\mathrm{R}$ - Point confinement of a bicomplex net $\left\{\xi_{\alpha}\right\}$ is a necessary but not sufficient condition for the convergence of the net in the classical sense (i.e., in the topology $\tau_{1}$ induced by the Euclidean norm). In fact, every eventually static net $\left\{\mathrm{x}_{\mathrm{k} \alpha}\right\}, 1 \leq \mathrm{k} \leq 4$, converges and therefore, $\mathrm{R}-$ Point confinement of $\left\{\xi_{\alpha}\right\}$ to $\xi$ implies convergence of $\left\{\xi_{\alpha}\right\}$ to $\xi$ in the norm. To verify insufficiency, consider the bicomplex net $\left\{\xi_{\alpha}\right\}$ on the directed set $\left(\mathrm{Q}^{+}, \geq\right)$of positive rationals (with usual ordering) defined as follows:

$$
\xi_{\alpha}=\mathrm{x}_{1 \alpha}+\mathrm{i}_{1} \mathrm{x}_{2 \alpha}+\mathrm{i}_{2} \mathrm{x}_{3 \alpha}+\mathrm{i}_{1} \mathrm{i}_{2} \mathrm{x}_{4 \alpha},
$$

where $\mathrm{x}_{\mathrm{k} \alpha}=\mathrm{k}+1 / \alpha, 1 \leq \mathrm{k} \leq 4$.

The net converges to the point $\xi=1+\mathrm{i}_{1} 2+\mathrm{i}_{2} 3+\mathrm{i}_{1} \mathrm{i}_{2} 4$ in the norm but not $\mathrm{R}$ - Point confined to $\xi$. As a matter of fact, no member of $\left\{\xi_{\alpha}\right\}$ belongs to the line segment

$$
\left(1+\mathrm{i}_{1} 2+\mathrm{i}_{2} 3+\mathrm{i}_{1} \mathrm{i}_{2}(4-\varepsilon), 1+\mathrm{i}_{1} 2+\mathrm{i}_{2} 3+\mathrm{i}_{1} \mathrm{i}_{2}(4+\varepsilon)\right)_{\mathrm{R}} .
$$

\subsection{Theorem}

A bicomplex net

$$
\left\{\xi_{\alpha}\right\}=\left\{x_{1 \alpha}+i_{1} x_{2 \alpha}+i_{2} x_{3 \alpha}+i_{1} i_{2} x_{4 \alpha}\right\}
$$

is $R F$ confined to the frame $\left(x_{1}=a\right)$ if and only if the net $\left\{\mathrm{x}_{1 \alpha}\right\}$ converges to a.

Proof: Assume that $\left\{\mathrm{x}_{1 \alpha}\right\}$ converges to a. Given $\varepsilon>0$, let

$$
\mathrm{B}_{\varepsilon}=\left\{\xi: \xi=\mathrm{x}_{1}+\mathrm{i}_{1} \mathrm{x}_{2}+\mathrm{i}_{2} \mathrm{x}_{3}+\mathrm{i}_{1} \mathrm{i}_{2} \mathrm{x}_{4} ; \mathrm{a}-\varepsilon<\mathrm{x}_{1}<\mathrm{a}+\varepsilon\right\}(3.1)
$$

be the member of $J_{1}$ containing the frame $\left(x_{1}=a\right)$.

Since, $\left\{x_{1 \alpha}\right\}$ converges to a, $\exists$ an index $\beta \in \mathrm{D}$ such that $\forall \mathrm{x}_{\mathrm{p}}, \mathrm{y}_{\mathrm{p}} \in \mathrm{C}_{0}, 1 \leq \mathrm{p} \leq 3$

$$
\begin{aligned}
& \mathrm{x}_{1 \alpha} \in(\mathrm{a}-\varepsilon, \mathrm{a}+\varepsilon), \quad \forall \alpha \geq \beta \\
& \Rightarrow \mathrm{a}-\varepsilon<\mathrm{x}_{1 \alpha}<\mathrm{a}+\varepsilon, \quad \forall \alpha \geq \beta \\
& \Rightarrow(\mathrm{a}-\varepsilon)+\mathrm{i}_{1} \mathrm{x}_{2}+\mathrm{i}_{2} \mathrm{x}_{3}+\mathrm{i}_{1} \mathrm{i}_{2} \mathrm{x}_{4} \\
& \qquad \prec_{\mathrm{R}} \mathrm{x}_{1 \alpha}+\mathrm{i}_{1} \mathrm{x}_{2 \alpha}+\mathrm{i}_{2} \mathrm{x}_{3 \alpha}+\mathrm{i}_{1} \mathrm{i}_{2} \mathrm{x}_{4 \alpha} \\
& \text { and } \mathrm{x}_{1 \alpha}+\mathrm{i}_{1} \mathrm{x}_{2 \alpha}+\mathrm{i}_{2} \mathrm{x}_{3 \alpha}+\mathrm{i}_{1} \mathrm{i}_{2} \mathrm{x}_{4 \alpha} \\
& \qquad \prec_{\mathrm{R}}(\mathrm{a}+\varepsilon)+\mathrm{i}_{1} \mathrm{y}_{2}+\mathrm{i}_{2} \mathrm{y}_{3}+\mathrm{i}_{1} \mathrm{i}_{2} \mathrm{y}_{4} \\
& \Rightarrow \mathrm{x}_{1 \alpha}+\mathrm{i}_{1} \mathrm{x}_{2 \alpha}+\mathrm{i}_{2} \mathrm{x}_{3 \alpha}+\mathrm{i}_{1} \mathrm{i}_{2} \mathrm{x}_{4 \alpha} \\
& \in\left(\mathrm{a}-\varepsilon+\mathrm{i}_{1} \mathrm{x}_{2}+\mathrm{i}_{2} \mathrm{x}_{3}+\mathrm{i}_{1} \mathrm{i}_{2} \mathrm{x}_{4}, \mathrm{a}+\varepsilon+\mathrm{i}_{1} \mathrm{y}_{2}+\mathrm{i}_{2} \mathrm{y}_{3}+\mathrm{i}_{1} \mathrm{i}_{2} \mathrm{y}_{4}\right)_{\mathrm{R}} \\
& \forall \mathrm{x}_{\mathrm{p}}, \mathrm{y}_{\mathrm{p}} \in \mathrm{C}_{0}, 1 \leq \mathrm{p} \leq 3 \text { and } \forall \alpha \geq \beta
\end{aligned}
$$

So that the net $\left\{\xi_{\alpha}\right\}=\left\{x_{1 \alpha}+i_{1} x_{2 \alpha}+i_{2} x_{3 \alpha}+i_{1} i_{2} x_{4 \alpha}\right\}$ is eventually in $\mathrm{B}_{\varepsilon}$.

Since $\varepsilon>0$ is arbitrary and every member of $\mathrm{J}_{1}$ contains a $\mathrm{B}_{\varepsilon}$ (for some $\varepsilon>0$ ), $\left\{\xi_{\alpha}\right\}$ is RF confined to the frame $\left(x_{1}=a\right)$.

Conversely, let the bicomplex net

$$
\left\{\xi_{\alpha}\right\}=\left\{x_{1 \alpha}+i_{1} x_{2 \alpha}+i_{2} x_{3 \alpha}+i_{1} i_{2} x_{4 \alpha}\right\}
$$

be RF confined to the frame $\left(x_{1}=a\right)$.

Therefore, the bicomplex net

$$
\left\{\xi_{\alpha}\right\}=\left\{x_{1 \alpha}+i_{1} x_{2 \alpha}+i_{2} x_{3 \alpha}+i_{1} i_{2} x_{4 \alpha}\right\}
$$

is eventually in every member of $J_{1}$ containing the frame $\left(x_{1}=a\right)$.

In particular, $\left\{\xi_{\alpha}\right\}$ is eventually in $\mathrm{B}_{\varepsilon}(\varepsilon>0)$ defined by (3.1).

Thus, $\exists \beta \in \mathrm{D}$ such that

$$
\begin{aligned}
\xi_{\alpha}=\mathrm{x}_{1 \alpha}+\mathrm{i}_{1} \mathrm{x}_{2 \alpha}+\mathrm{i}_{2} \mathrm{x}_{3 \alpha}+\mathrm{i}_{1} \mathrm{i}_{2} \mathrm{x}_{4 \alpha} \in \mathrm{B}_{\varepsilon}, \quad \forall \alpha \geq \beta \\
\quad \Rightarrow \mathrm{a}-\varepsilon<\mathrm{x}_{1 \alpha}<\mathrm{a}+\varepsilon, \quad \forall \alpha \geq \beta \\
\quad \Rightarrow\left\{\mathrm{x}_{1 \alpha}\right\} \rightarrow \mathrm{a} .
\end{aligned}
$$


Hence the theorem.

\subsection{Theorem}

A bicomplex net

$$
\left\{\xi_{\alpha}\right\}=\left\{x_{1 \alpha}+i_{1} x_{2 \alpha}+i_{2} x_{3 \alpha}+i_{1} i_{2} x_{4 \alpha}\right\}
$$

is RP confined to the plane $\left(x_{1}=a, x_{2}=b\right)$ if and only if the net $\left\{x_{1 \alpha}\right\}$ is eventually static on 'a' and net $\left\{x_{2 \alpha}\right\}$ converges to ' $b$ '.

Proof: Let the net $\left\{x_{1 \alpha}\right\}$ be eventually static on 'a' and the net $\left\{\mathrm{x}_{2 \alpha}\right\}$ converge to ' $\mathrm{b}$ '.

Since $\left\{x_{1 \alpha}\right\}$ is eventually static on $a, \exists \beta \in D$, such that $\forall \alpha \geq \beta, \quad x_{1 \alpha}=a$.

Given $\varepsilon>0$, let

$I_{\varepsilon}=\left\{\xi: \xi=a+i_{1} x_{2}+i_{2} x_{3}+i_{1} i_{2} x_{4} ; b-\varepsilon<x_{2}<b+\varepsilon\right\}(3.2)$

be a member of $\mathrm{J}_{2}$ containing the plane $\left(\mathrm{x}_{1}=\mathrm{a}, \mathrm{x}_{2}=\mathrm{b}\right)$.

As the net $\left\{x_{2 \alpha}\right\}$ converges to $b$, there exists some $\gamma \in \mathrm{D}$ such that

$$
\mathrm{x}_{2 \alpha} \in(\mathrm{b}-\varepsilon, \mathrm{b}+\varepsilon), \forall \alpha \geq \gamma
$$

Since $\beta, \gamma \in \mathrm{D}$, there exists some $\delta \in \mathrm{D}$ such that $\delta \geq \beta$ and $\delta \geq \gamma$.

Therefore, $\mathrm{x}_{1 \alpha}=\mathrm{a}$ and $\mathrm{x}_{2 \alpha} \in(\mathrm{b}-\varepsilon, \mathrm{b}+\varepsilon), \forall \alpha \geq \delta$.

$$
\Rightarrow \mathrm{b}-\varepsilon<\mathrm{x}_{2 \alpha}<\mathrm{b}+\varepsilon, \quad \forall \alpha \geq \delta
$$

$$
\Rightarrow \mathrm{x}_{1 \alpha}+\mathrm{i}_{1} \mathrm{x}_{2 \alpha}+\mathrm{i}_{2} \mathrm{x}_{3 \alpha}+\mathrm{i}_{1} \mathrm{i}_{2} \mathrm{x}_{4 \alpha}
$$

$\in\left(a+i_{1}(b-\varepsilon)+i_{2} x_{3}+i_{1} i_{2} x_{4}, a+i_{1}(b+\varepsilon)+i_{2} y_{3}+i_{1} i_{2} y_{4}\right)_{R}$

for any $\mathrm{x}_{3}, \mathrm{x}_{4}, \mathrm{y}_{3}, \mathrm{y}_{4} \in \mathrm{C}_{0}, \forall \alpha \geq \delta$.

So that the bicomplex net

$$
\left\{\xi_{\alpha}\right\}=\left\{\mathrm{x}_{1 \alpha}+\mathrm{i}_{1} \mathrm{x}_{2 \alpha}+\mathrm{i}_{2} \mathrm{x}_{3 \alpha}+\mathrm{i}_{1} \mathrm{i}_{2} \mathrm{x}_{4 \alpha}\right\}
$$

is eventually in $I_{\varepsilon}$.

Since $\varepsilon>0$ is arbitrary and every member of $\mathrm{J}_{2}$ contains an $I_{\varepsilon}$ for some $\varepsilon>0$, the bicomplex net $\left\{\xi_{\alpha}\right\}$ is RP confined to the plane $\left(x_{1}=a, x_{2}=b\right)$.

Conversely, suppose that the bicomplex net

$$
\left\{\xi_{\alpha}\right\}=\left\{x_{1 \alpha}+i_{1} x_{2 \alpha}+i_{2} x_{3 \alpha}+i_{1} i_{2} x_{4 \alpha}\right\}
$$

is RP confined to the plane $\left(\mathrm{x}_{1}=\mathrm{a}, \mathrm{x}_{2}=\mathrm{b}\right)$.

Therefore, it is eventually in every member of the type $\mathrm{I}_{\varepsilon}(\varepsilon>0)$ defined by (3.2), of the family $\mathrm{J}_{2}$ containing the plane $\left(\mathrm{x}_{1}=\mathrm{a}, \mathrm{x}_{2}=\mathrm{b}\right)$.

So that for given $\varepsilon>0$, there exists some $\beta \in \mathrm{D}$ such that

$$
\begin{gathered}
\left\{\xi_{\alpha}\right\} \in \mathrm{I}_{\varepsilon}, \forall \alpha \geq \beta \\
\Rightarrow \mathrm{x}_{1 \alpha}=\mathrm{a} \quad \text { and } \mathrm{x}_{2 \alpha} \in(\mathrm{b}-\varepsilon, \mathrm{b}+\varepsilon), \forall \alpha \geq \beta
\end{gathered}
$$

Therefore, the net $\left\{x_{1 \alpha}\right\}$ is eventually static on a and the net $\left\{\mathrm{x}_{2 \alpha}\right\}$ converges to $\mathrm{b}$.

On the similar lines, the following theorems can be proved.

\subsection{Theorem}

A bicomplex net $\left\{\xi_{\alpha}\right\}=\left\{\mathrm{x}_{1 \alpha}+\mathrm{i}_{1} \mathrm{x}_{2 \alpha}+\mathrm{i}_{2} \mathrm{x}_{3 \alpha}+\mathrm{i}_{1} \mathrm{i}_{2} \mathrm{x}_{4 \alpha}\right\}$ is RL confined to the line $\left(\mathrm{x}_{1}=\mathrm{a}, \mathrm{x}_{2}=\mathrm{b}, \mathrm{x}_{3}=\mathrm{c}\right)$ if and only if the nets $\left\{\mathrm{x}_{1 \alpha}\right\}$ and $\left\{\mathrm{x}_{2 \alpha}\right\}$ are eventually static on $\mathrm{a}$ and $\mathrm{b}$, respectively and the net $\left\{\mathrm{x}_{3 \alpha}\right\}$ converges to $\mathrm{c}$.

\subsection{Theorem}

A bicomplex net $\left\{\xi_{\alpha}\right\}=\left\{\mathrm{x}_{1 \alpha}+\mathrm{i}_{1} \mathrm{x}_{2 \alpha}+\mathrm{i}_{2} \mathrm{x}_{3 \alpha}+\mathrm{i}_{1} \mathrm{i}_{2} \mathrm{x}_{4 \alpha}\right\}$ is $\mathrm{R}$ - Point confined to the bicomplex point $a+i_{1} b+i_{2} c+i_{1} i_{2} d$ if and only if the nets $\left\{x_{1 \alpha}\right\},\left\{x_{2 \alpha}\right\}$, and $\left\{\mathrm{x}_{3 \alpha}\right\}$ are eventually static on $\mathrm{a}, \mathrm{b}$ and $\mathrm{c}$, respectively and the net $\left\{\mathrm{x}_{4 \alpha}\right\}$ is converges to $\mathrm{d}$.

\subsection{Theorem}

(i) Every R - Point confined bicomplex net is RL confined.

(ii) Every RL confined bicomplex net is RP confined.

(iii) Every RP confined bicomplex net is RF confined.

The converses of these implications are not true, in general.

Proof: In fact, if a bicomplex net $\left\{\xi_{\alpha}\right\}$ is $\mathrm{R}$ - Point confined to the bicomplex point $a+i_{1} b+i_{2} c+i_{1} i_{2} d$, then it is RL confined to the line $\left(x_{1}=a, x_{2}=b, x_{3}=c\right)$. Similarly, a bicomplex net which is RL confined to the line $\left(x_{1}=a, x_{2}=b, x_{3}=c\right)$ is $R P$ confined to the plane $\left(\mathrm{x}_{1}=\mathrm{a}, \mathrm{x}_{2}=\mathrm{b}\right)$ and a bicomplex net which is RP confined to the plane $\left(x_{1}=a, x_{2}=b\right)$ is RF confined to the frame $\left(x_{1}=a\right)$.

That the converse is not true, in general, is shown with the help of the two examples below.

\subsection{Example}

Consider the directed set $\left(\mathrm{Q}^{+}, \geq\right)$. Define the bicomplex net $\left\{\xi_{\alpha}\right\}$ as follows:

such that

$$
\left\{\xi_{\alpha}\right\}=\left\{x_{1 \alpha}+i_{1} x_{2 \alpha}+i_{2} x_{3 \alpha}+i_{1} i_{2} x_{4 \alpha}\right\}
$$

$$
\mathrm{x}_{1 \alpha}=\mathrm{a}-\mathrm{x}_{\alpha}, \quad \mathrm{x}_{2 \alpha}=1 / \alpha, \quad \mathrm{x}_{3 \alpha}=\alpha+1
$$

and $\mathrm{x}_{4 \alpha}=\alpha, \forall \alpha \in \mathrm{Q}^{+}$,

where the net $\left\{x_{\alpha}\right\}$ is eventually static on 0 .

Therefore, the net $\left\{\mathrm{x}_{1 \alpha}\right\}$ is eventually static on ' $\mathrm{a}$ ' and the net $\left\{\mathrm{x}_{2 \alpha}\right\}$ converges on ' 0 '. So that the bicomplex net $\left\{\xi_{\alpha}\right\}$ is RP confined to the plane $\left(x_{1}=a, x_{2}=b\right)$. Since, the net $\left\{x_{1 \alpha}\right\}$ is eventually static on ' $a$ '. Therefore, the bicomplex net $\left\{\xi_{\alpha}\right\}$ is eventually in every member of the family $\mathrm{J}_{1}$ containing the frame $\left(\mathrm{x}_{1}=\mathrm{a}\right)$. Hence, the bicomplex net $\left\{\xi_{\alpha}\right\}$ is RF confined to the frame $\left(x_{1}=a\right)$.

\subsection{Example}

Consider the bicomplex net

$$
\left\{\xi_{\alpha}\right\}=\left\{x_{1 \alpha}+i_{1} x_{2 \alpha}+i_{2} x_{3 \alpha}+i_{1} i_{2} x_{4 \alpha}\right\}
$$


such that

$$
\mathrm{x}_{1 \alpha}=\mathrm{a}-(1 / \alpha), \mathrm{x}_{2 \alpha}=\alpha+1, \quad \mathrm{x}_{3 \alpha}=\alpha+2
$$

and $\mathrm{x}_{4 \alpha}=\alpha+3, \forall \alpha \in \mathrm{Q}^{+}$.

This bicomplex net is RF confined to the frame $\left(x_{1}=a\right)$. The component net $\left\{\mathrm{x}_{1 \alpha}\right\}$ converges to ' $\mathrm{a}$ ' but component net $\left\{\mathrm{x}_{2 \alpha}\right\}$ is not convergent. Therefore, the bicomplex net $\left\{\xi_{\alpha}\right\}=\left\{x_{1 \alpha}+i_{1} x_{2 \alpha}+i_{2} x_{3 \alpha}+i_{1} i_{2} x_{4 \alpha}\right\}$ is not RP confined to any plane contained in the frame $\left(\mathrm{x}_{1}=\mathrm{a}\right)$.

\section{Confinements of Bicomplex Nets in Idempotent Order Topology}

In this section, we assume $\mathrm{C}_{2}$ to be furnished with the idempotent order topology (cf. [4]). Hence, the net

$$
\left\{\xi_{\alpha}\right\}=\left\{\mathrm{x}_{1 \alpha}+\mathrm{i}_{1} \mathrm{x}_{2 \alpha}+\mathrm{i}_{2} \mathrm{x}_{3 \alpha}+\mathrm{i}_{1} \mathrm{i}_{2} \mathrm{x}_{4 \alpha}\right\}
$$

will be treated as the net $\left\{\xi_{\alpha}\right\}=\left\{{ }^{1} \xi_{1} e_{1}{ }^{2} \xi_{\mathrm{e}_{2}}\right\}$, where

$$
\begin{aligned}
{ }^{1} \xi_{\alpha} \mathrm{e}_{1}+{ }^{2} \xi_{\alpha} \mathrm{e}_{2}= & {\left[\left(\mathrm{x}_{1 \alpha}+\mathrm{x}_{4 \alpha}\right)+\mathrm{i}_{1}\left(\mathrm{x}_{2 \alpha}-\mathrm{x}_{3 \alpha}\right)\right] \mathrm{e}_{1} } \\
& +\left[\left(\mathrm{x}_{1 \alpha}-\mathrm{x}_{4 \alpha}\right)+\mathrm{i}_{1}\left(\mathrm{x}_{2 \alpha}+\mathrm{x}_{3 \alpha}\right)\right] \mathrm{e}_{2}
\end{aligned}
$$

For the sake of brevity, we shall express the numbers the numbers $\mathrm{x}_{1}+\mathrm{x}_{4}$ and $\mathrm{x}_{2}-\mathrm{x}_{3}$ as $\operatorname{Re}^{1} \xi$ and $\operatorname{Im}^{1} \xi$, respectively. Thus $\left(\operatorname{Re}^{1} \xi_{1}=\mathrm{a}\right)$ denote the frame $\mathrm{x}_{1}+\mathrm{x}_{4}=\mathrm{a}$, whereas $\left\{\operatorname{Re}^{1} \xi_{\alpha}\right\}$ denote the net $\left\{\mathrm{x}_{1 \alpha}+\mathrm{x}_{4 \alpha}\right\}$ and so on. Under these notations, (4.1) can be rewritten as

$$
\begin{aligned}
{ }^{1} \xi_{\alpha} \mathrm{e}_{1}+{ }^{2} \xi_{\alpha} \mathrm{e}_{2}= & \left(\operatorname{Re}^{1} \xi_{\alpha}+\mathrm{i}_{1} \operatorname{Im}{ }^{1} \xi_{\alpha}\right) \mathrm{e}_{1} \\
& +\left(\operatorname{Re}^{2} \xi_{\alpha}+\mathrm{i}_{1} \operatorname{Im}{ }^{2} \xi_{\alpha}\right) \mathrm{e}_{2}
\end{aligned}
$$

Note that for the net $\left\{\operatorname{Re}^{1} \xi_{\alpha}\right\}$ to be convergent, either both the nets $\left\{\mathrm{x}_{1 \alpha}\right\}$ and $\left\{\mathrm{x}_{4 \alpha}\right\}$ are convergent or both nets $\left\{x_{1 \alpha}\right\}$ and $\left\{x_{4 \alpha}\right\}$ are divergent but $\left\{\operatorname{Re}^{1} \xi_{\alpha}\right\}$ is convergent. Similarly, for net $\left\{\operatorname{Im}^{1} \xi_{\alpha}\right\}$ will be convergent if either both the nets $\left\{\mathrm{x}_{2 \alpha}\right\}$ and $\left\{\mathrm{x}_{3 \alpha}\right\}$ are convergent or both nets $\left\{\mathrm{x}_{2 \alpha}\right\}$ and $\left\{\mathrm{x}_{3 \alpha}\right\}$ are divergent but $\left\{\operatorname{Im}^{1} \xi_{\alpha}\right\}$ is convergent. The convergence of nets $\left\{\operatorname{Re}^{2} \xi_{\alpha}\right\}$ and $\left\{\operatorname{Im}^{2} \xi_{\alpha}\right\}$ can be similarly interpreted.

\subsection{ID - Frame Confinement (ID - F Confinement)}

A bicomplex net $\left\{\xi_{\alpha}\right\}=\left\{{ }^{1} \xi_{\alpha} \mathrm{e}_{1}+{ }^{2} \xi_{\alpha} \mathrm{e}_{2}\right\}$ is said to be ID - Frame confined (in short, ID - F confined) to the ID - frame $\left(\operatorname{Re}^{1} \xi=\mathrm{a}\right)$ if it is eventually in every member of the family $\mathrm{N}_{1}$ (of open ID - space segments) that contains the ID - frame $\left(\operatorname{Re}^{1} \xi=\mathrm{a}\right)$.

\subsection{ID - Plane Confinement (ID - P Confinement)}

A bicomplex net $\left\{\xi_{\alpha}\right\}=\left\{{ }^{1} \xi_{\alpha} \mathrm{e}_{1}+{ }^{2} \xi_{\alpha} \mathrm{e}_{2}\right\}$ is said to be ID - Plane confined (in short, ID - $\mathrm{P}$ confined) to the ID
- plane $\left(\operatorname{Re}^{1} \xi=\mathrm{a}, \operatorname{Im}^{1} \xi=\mathrm{b}\right)$ if it is eventually in every member of the family $\mathrm{N}_{2}$ (of open ID - frame segments) that contains the ID - plane $\left(\operatorname{Re}^{1} \xi=a, \operatorname{Im}{ }^{1} \xi=b\right)$.

\subsection{ID - Line Confinement (ID - L Confinement)}

A bicomplex net $\left\{\xi_{\alpha}\right\}=\left\{{ }^{1} \xi_{\alpha} \mathrm{e}_{1}+{ }^{2} \xi_{\alpha} \mathrm{e}_{2}\right\}$ is said to be ID - Line confined (in short, ID - L confined) to the ID - line $\left(\operatorname{Re}^{1} \xi=\mathrm{a}, \operatorname{Im}^{1} \xi=\mathrm{b}, \operatorname{Re}^{2} \xi=\mathrm{c}\right)$ if it is eventually in every member of the family $\mathrm{N}_{3}$ (of open ID plane segments) containing the ID - line $\left(\operatorname{Re}^{1} \xi=\mathrm{a}, \operatorname{Im}^{1} \xi=\mathrm{b}, \operatorname{Re}^{2} \xi=\mathrm{c}\right)$.

\subsection{ID - Point Confinement}

A bicomplex net $\left\{\xi_{\alpha}\right\}=\left\{{ }^{1} \xi_{\alpha} \mathrm{e}_{1}+{ }^{2} \xi_{\alpha} \mathrm{e}_{2}\right\}$ is said to be ID - Point confined to the point $\xi={ }^{1} \xi_{\mathrm{e}_{1}}+{ }^{2} \xi_{\mathrm{e}}$ if it is eventually in every member of the family $\mathrm{N}_{4}$ (of ID line segments) containing the point $\xi={ }^{1} \xi \mathrm{e}_{1}+{ }^{2} \xi \mathrm{e}_{2}$.

\subsection{Remark}

Note that if a bicomplex net $\left\{\xi_{\alpha}\right\}$ defined by (4.2) is ID - F confined to the frame $\left(\operatorname{Re}^{1} \xi=\mathrm{a}\right)$, it cannot be eventually in any member of the family $\mathrm{N}_{2}$ unless $\left\{\operatorname{Re}{ }^{1} \xi_{\alpha}\right\}$ is eventually static on ' $a$ '. Similar cases will arise with the other types of the confinements of the bicomplex nets with respect to the idempotent order topology.

\subsection{Theorem}

A bicomplex net $\left\{\xi_{\alpha}\right\}$ is ID - F confined to the ID frame $\left(\operatorname{Re}^{1} \xi=a\right)$ if and only if the net $\left\{\operatorname{Re}^{1} \xi_{\alpha}\right\}$ converges to a.

Proof: Assume that $\left\{\operatorname{Re}^{1} \xi_{\alpha}\right\}$ converges to a.

$$
\text { Given } \begin{aligned}
\varepsilon & >0, \text { let } \\
\mathrm{S}_{\varepsilon} & =\left\{\xi: \mathrm{a}-\varepsilon<\operatorname{Re}^{1} \xi<\mathrm{a}+\varepsilon\right\}
\end{aligned}
$$

be a member of $\mathrm{N}_{1}$ containing the ID - frame $\left(\operatorname{Re}^{1} \xi=a\right)$.

Since $\left\{\operatorname{Re}^{1} \xi_{\alpha}\right\} \rightarrow \mathrm{a}$, there exists an index $\beta \in \mathrm{D}$ such that

$$
\mathrm{a}-\varepsilon<\operatorname{Re}^{1} \xi<\mathrm{a}+\varepsilon, \quad \forall \alpha \geq \beta
$$

Hence, by the definition of $\prec$, we have $\forall \alpha \geq \beta$ and

$$
\begin{gathered}
\forall \mathrm{x}_{2}, \mathrm{y}_{2} \in \mathrm{C}_{2}, \\
\mathrm{a}-\varepsilon+\mathrm{i}_{1} \mathrm{x}_{2}<\left(\operatorname{Re}^{1} \xi\right)+\mathrm{i}_{1}\left(\operatorname{Im}^{1} \xi\right) \text { and } \\
\left(\operatorname{Re}^{1} \xi\right)+\mathrm{i}_{1}\left(\operatorname{Im}^{1} \xi\right)<\mathrm{a}+\varepsilon+\mathrm{i}_{1} \mathrm{y}_{2}
\end{gathered}
$$$$
\text { i.e, }\left(\left(\operatorname{Re}{ }^{1} \xi\right)+i_{1}\left(\operatorname{Im}{ }^{1} \xi\right)\right) e_{1}+\left(\left(\operatorname{Re}^{2} \xi\right)+i_{1}\left(\operatorname{Im}^{2} \xi\right)\right) e_{2}
$$

$\in\left(\left(a-\varepsilon+i_{1} x_{2}\right) e_{1}+\left(x_{3}+i_{1} x_{4}\right) e_{2},\left(a+\varepsilon+i_{1} y_{2}\right) e_{1}+\left(y_{3}+i_{1} y_{4}\right) e_{2}\right)_{I D}$

for any $\mathrm{x}_{3}, \mathrm{x}_{4}, \mathrm{y}_{3}$ and $\mathrm{y}_{4} \in \mathrm{C}_{0}, \forall \alpha \geq \beta$.

So that the bicomplex net $\left\{\xi_{\alpha}\right\}$ is eventually in $\mathrm{S}_{\varepsilon}$. Since $\varepsilon>0$ is arbitrary and every member of $\mathrm{N}_{1}$ 
contains $\mathrm{S}_{\varepsilon}$ for some $\varepsilon>0$, by definition, $\left\{\xi_{\alpha}\right\}$ is ID F confined to the ID - frame $\left(\operatorname{Re}^{1} \xi=\mathrm{a}\right)$.

Conversely, let the bicomplex net $\left\{\xi_{\alpha}\right\}=\left\{{ }^{1} \xi_{\alpha} \mathrm{e}_{1}+{ }^{2} \xi_{\alpha} \mathrm{e}_{2}\right\}$ be ID $-\mathrm{F}$ confined to the ID - frame $\left(\operatorname{Re}^{1} \xi=\mathrm{a}\right)$.

By definition, it is eventually in every member of $\mathrm{B}_{6}$ (in fact, of $\mathrm{N}_{1}$ ) containing the frame $\left(\operatorname{Re}^{1} \xi=\mathrm{a}\right)$. In particular, it is eventually in $\mathrm{S}_{\varepsilon}$, for every $\varepsilon$, defined by (4.3).

Thus, $\exists \beta \in \mathrm{D}$ such that $\xi_{\alpha} \in \mathrm{S}_{\varepsilon}, \forall \alpha \geq \beta$, i.e., such that $\forall \mathrm{x}_{2}, \mathrm{x}_{3}, \mathrm{x}_{4}, \mathrm{y}_{2}, \mathrm{y}_{3}, \mathrm{y}_{4} \in \mathrm{C}_{0}$ and $\forall \alpha \geq \beta$

$$
\xi_{\alpha} \in\left(\begin{array}{l}
\left(a-\varepsilon+i_{1} x_{2}\right) e_{1}+\left(x_{3}+i_{1} x_{4}\right) e_{2}, \\
\left(a+\varepsilon+i_{1} x_{2}\right) e_{1}+\left(x_{3}+i_{1} x_{4}\right) e_{2}
\end{array}\right) \text { ID }
$$

By definition of $\mathrm{N}_{1}$ and $\mathrm{S}_{\varepsilon}$, we infer

$$
\begin{aligned}
& \mathrm{a}-\varepsilon<\operatorname{Re}^{1} \xi_{\alpha}<\mathrm{a}+\varepsilon \\
\Rightarrow & \operatorname{Re}^{1} \xi_{\alpha} \in(\mathrm{a}-\varepsilon, \mathrm{a}+\varepsilon), \quad \forall \alpha \geq \beta \\
\Rightarrow & \left\{\operatorname{Re}^{1} \xi_{\alpha}\right\} \rightarrow \mathrm{a} .
\end{aligned}
$$

Hence the theorem.

\subsection{Theorem}

A bicomplex net $\left\{\xi_{\alpha}\right\}$ is ID - P confined to the ID plane $\left(\operatorname{Re}^{1} \xi=\mathrm{a}, \operatorname{Im}^{1} \xi=\mathrm{b}\right)$ if and only if the net $\left\{\operatorname{Re}{ }^{1} \xi_{\alpha}\right\}$ is eventually static on a and the net $\left\{\operatorname{Im}{ }^{1} \xi_{\alpha}\right\}$ converges to $b$.

Proof: Suppose that the net $\left\{\operatorname{Re}^{1} \xi_{\alpha}\right\}$ is eventually static at a and the net $\left\{\operatorname{Im}{ }^{1} \xi_{\alpha}\right\}$ converges to $b$.

Since the net $\left\{\operatorname{Re}^{1} \xi_{\alpha}\right\}$ is eventually static on a, $\exists \beta \in \mathrm{D}$, such that $\forall \alpha \geq \beta, \operatorname{Re}^{1} \xi_{\alpha}=\mathrm{a}$.

Given $\varepsilon>0$, let

$$
\mathrm{F}_{\varepsilon}=\left\{\xi: \operatorname{Re}^{1} \xi=\mathrm{a}, \mathrm{b}-\varepsilon<\operatorname{Im}^{1} \xi<\mathrm{b}+\varepsilon\right\}
$$

be a member of $\mathrm{N}_{2}$ containing the ID - plane $\left(\operatorname{Re}^{1} \xi=\mathrm{a}, \operatorname{Im}^{1} \xi=\mathrm{b}\right)$.

Since the net $\left\{\operatorname{Im}{ }^{1} \xi_{\alpha}\right\}$ converges to $b$, there exists some $\gamma \in \mathrm{D}$ such that $\operatorname{Im}^{1} \xi_{\alpha} \in(\mathrm{b}-\varepsilon, \mathrm{b}+\varepsilon), \forall \alpha \geq \gamma$.

Since $\beta, \gamma \in \mathrm{D}$. Then, there exists some $\delta \in \mathrm{D}$ such that $\delta \geq \beta$ and $\delta \geq \gamma$.

Therefore, $\operatorname{Re}^{1} \xi=\mathrm{a}$ and $\operatorname{Im}^{1} \xi_{\alpha} \in(\mathrm{b}-\varepsilon, \mathrm{b}+\varepsilon), \forall \alpha \geq \delta$.

$$
\begin{gathered}
\xi_{\alpha} \in\left(\begin{array}{l}
\left(\mathrm{a}+\mathrm{i}_{1}(\mathrm{~b}-\varepsilon)\right) \mathrm{e}_{1}+\left(\mathrm{x}_{3}+\mathrm{i}_{1} \mathrm{x}_{4}\right) \mathrm{e}_{2}, \\
\left(\mathrm{a}+\mathrm{i}_{1}(\mathrm{~b}+\varepsilon)\right) \mathrm{e}_{1}+\left(\mathrm{x}_{3}+\mathrm{i}_{1} \mathrm{x}_{4}\right) \mathrm{e}_{2}
\end{array}\right)_{I D} \\
\forall \mathrm{x}_{3}, \mathrm{x}_{4}, \mathrm{y}_{3}, \mathrm{y}_{4} \in \mathrm{C}_{0}, \quad \forall \alpha \geq \delta .
\end{gathered}
$$

Therefore, the net $\left\{\xi_{\alpha}\right\}$ is eventually in $\mathrm{F}_{\varepsilon}$.

Since $\varepsilon>0$ is arbitrary and every member of $\mathrm{N}_{2}$ contains an $\mathrm{F}_{\varepsilon}$ for some $\varepsilon>0$, by the definition, the bicomplex net $\left\{\xi_{\alpha}\right\}$ is ID - P confined to the ID - plane $\left(\operatorname{Re}^{1} \xi=\mathrm{a}, \operatorname{Im}^{1} \xi=\mathrm{b}\right)$.
Conversely, suppose that the bicomplex net $\left\{\xi_{\alpha}\right\}$ is ID - $\mathrm{P}$ confined to the ID - plane $\left(\operatorname{Re}^{1} \xi=\mathrm{a}, \operatorname{Im}^{1} \xi=\mathrm{b}\right)$.

Therefore, the bicomplex net $\left\{\xi_{\alpha}\right\}$ is eventually in every member of the family $\mathrm{N}_{2}$ containing the ID - plane $\left(\operatorname{Re}^{1} \xi=a, \operatorname{Im}^{1} \xi=b\right)$. In particular, the net is eventually in every open ID - frame segment $\mathrm{F}_{\varepsilon},(\varepsilon>0)$, defined by (4.4) containing the ID - plane $\left(\operatorname{Re}^{1} \xi=a, \operatorname{Im}^{1} \xi=b\right)$.

Given $\varepsilon>0$, there exists some $\beta \in \mathrm{D}$ such that $\left\{\xi_{\alpha}\right\} \in \mathrm{F}_{\varepsilon}, \quad \forall \alpha \geq \beta$.

Therefore, by definition of $\mathrm{F}_{\varepsilon}, \mathrm{x}_{1 \alpha}=\mathrm{a}$ and $\mathrm{x}_{2 \alpha} \in(\mathrm{b}-\varepsilon, \mathrm{b}+\varepsilon), \quad \forall \alpha \geq \beta$.

Hence the theorem.

On similar lines, the following theorems can be proved.

\subsection{Theorem}

A bicomplex net $\left\{\xi_{\alpha}\right\}$ is ID - L confined to the ID line $\left(\operatorname{Re}^{1} \xi=\mathrm{a}, \operatorname{Im}^{1} \xi=\mathrm{b}, \operatorname{Re}^{1} \xi=\mathrm{c}\right)$ if the nets $\left\{\operatorname{Re}{ }^{1} \xi_{\alpha}\right\}$ and $\left\{\operatorname{Im}{ }^{1} \xi_{\alpha}\right\}$ are eventually static on a and $b$, respectively and $\left\{\operatorname{Re}^{2} \xi_{\alpha}\right\}$ converges to c.

\subsection{Theorem}

A bicomplex net $\left\{\xi_{\alpha}\right\}$ is ID - Point confined to the point $\xi=\left(a+i_{1} b\right) e_{1}+\left(c+i_{1} d\right) e_{2}$ if the nets $\left\{\operatorname{Re}^{1} \xi_{\alpha}\right\}$, $\left\{\operatorname{Im}{ }^{1} \xi_{\alpha}\right\}$ and $\left\{\operatorname{Re}^{2} \xi_{\alpha}\right\}$ are eventually static on a, b and $\mathrm{c}$, respectively and the net $\left\{\operatorname{Im}^{2} \xi_{\alpha}\right\}$ converges to d.

\subsection{Theorem}

(i) Every ID - Point confined bicomplex net is ID - L confined.

(ii) Every ID - L confined bicomplex net ID - P confined.

(iii) Every ID - P confined bicomplex net ID - F confined.

The converses of these implications are not true, in general.

Proof: In fact, if a bicomplex net $\left\{\xi_{\alpha}\right\}$ is ID - Point confined to the point $\xi=\left(a+i_{1} b\right) e_{1}+\left(c+i_{1} d\right) e_{2}$, say, then it is ID $-\mathrm{L}$ confined to the ID - line $\left(\operatorname{Re}^{1} \xi=\mathrm{a}, \operatorname{Im}{ }^{1} \xi=\mathrm{b}, \operatorname{Re}^{1} \xi=\mathrm{c}\right)$. Further, a bicomplex net which is ID - $\mathrm{L}$ confined to the ID - line $\left(\operatorname{Re}^{1} \xi=\mathrm{a}, \operatorname{Im}{ }^{1} \xi=\mathrm{b}, \operatorname{Re}^{1} \xi=\mathrm{c}\right)$ is ID $-\mathrm{P}$ confined to the ID - plane $\left(\operatorname{Re}^{1} \xi=a, \operatorname{Im}^{1} \xi=b\right)$. Furthermore, a bicomplex net which is ID - P confined to the ID - plane $\left(\operatorname{Re}^{1} \xi=\mathrm{a}, \operatorname{Im}{ }^{1} \xi=\mathrm{b}\right)$ is ID $-\mathrm{F}$ confined to the ID frame $\left(\operatorname{Re}^{1} \xi=\mathrm{a}\right)$.

To show that that the converse of these implications are not true, in general, we give below, in particular, an example of ID $-\mathrm{F}$ confined net which is also ID $-\mathrm{P}$ confined and 
an example of an ID - F confined net which is not ID - P confined.

\subsection{Example} net

Consider the directed set $\left(\mathrm{Q}^{+}, \geq\right)$. Define the bicomplex

$$
\left\{\xi_{\alpha}\right\}=\left\{\begin{array}{l}
\mathrm{a}-\mathrm{x}_{\alpha}+\alpha^{2}+\mathrm{i}_{1}\left(\mathrm{a}-1 / \alpha+\alpha^{3}\right) \\
+\mathrm{i}_{2}\left(-\mathrm{a}-1 / \alpha+\alpha^{3}\right)+\mathrm{i}_{1} \mathrm{i}_{2}\left(\mathrm{a}-\mathrm{x}_{\alpha}-\alpha^{2}\right)
\end{array}\right\} \forall \alpha \in \mathrm{Q}^{+},
$$

where $\left\{\mathrm{x}_{\alpha}\right\}$ is eventually static on 0 .

By (4.1), the net $\left\{\operatorname{Re}^{1} \xi_{\alpha}\right\}$ is eventually static on $2 \mathrm{a}$ and hence converges to $2 \mathrm{a}$, the bicomplex net $\left\{\xi_{\alpha}\right\}$ is eventually in every member of the family $\mathrm{N}_{1}$ containing the ID - frame $\left(\operatorname{Re}^{1} \xi=2 \mathrm{a}\right)$. Hence the net is ID $-\mathrm{F}$ confined to the frame $\left(\operatorname{Re}^{1} \xi=2 \mathrm{a}\right)$.

Also, the net $\left\{\operatorname{Re}^{1} \xi_{\alpha}\right\}$ is eventually static on $2 \mathrm{a}$ and the net $\left\{\operatorname{Im}{ }^{1} \xi_{\alpha}\right\}$ converges to $2 \mathrm{a}$.

Therefore, bicomplex net $\left\{\xi_{\alpha}\right\}$ is ID - P confined to the ID - plane $\left(\operatorname{Re}^{1} \xi=2 \mathrm{a}, \operatorname{Im}^{1} \xi=2 \mathrm{~b}\right)$.

\subsection{Example}

Consider the bicomplex net

$$
\left\{\xi_{\alpha}\right\}=\left\{\begin{array}{c}
\left(\mathrm{a}-\mathrm{x}_{\alpha}+\alpha\right)+\mathrm{i}_{1}\left(1 / \alpha+\alpha^{2}\right) \\
+\mathrm{i}_{2}\left(-1 / \alpha+\alpha^{2}\right)+\mathrm{i}_{1} \mathrm{i}_{2}\left(\mathrm{a}-\mathrm{x}_{\alpha}-\alpha\right)
\end{array}\right\}
$$

By (4.1), the net $\left\{\operatorname{Re}^{1} \xi_{\alpha}\right\}$ is eventually static on $2 \mathrm{a}$ and the net $\left\{\operatorname{Im}{ }^{1} \xi_{\alpha}\right\}$ converges to 0 . Therefore, the bicomplex net $\left\{\xi_{\alpha}\right\}$ is ID - F confined to the ID - frame $\left(\operatorname{Re}^{1} \xi=2 \mathrm{a}\right)$.

Note that although the component net $\left\{\operatorname{Re}^{1} \xi_{\alpha}\right\}$ converges to $2 \mathrm{a}$, it is not eventually static on $2 \mathrm{a}$. Therefore, the bicomplex net $\left\{\xi_{\alpha}\right\}$ is not ID - P confined to any ID plane contained in the ID - frame $\left(\operatorname{Re}^{1} \xi=2 \mathrm{a}\right)$.

\section{Bicomplex Net and its Projection Nets}

This section is devoted to the study of relations between confinements of a bicomplex net and the convergence of its projection nets (cf.[7]) in the idempotent product topology (cf.[4]). Recall the definitions of the auxiliary complex spaces $A_{1}$ and $A_{2}$.

\subsection{Theorem}

A bicomplex net $\left\{\xi_{\alpha}\right\}$ converges to a bicomplex point $\xi$ in the idempotent product topology if and only if the net $\left\{{ }^{\mathrm{k}} \xi_{\alpha}\right\}$ in $\mathrm{A}_{\mathrm{k}}$ is confined to ${ }^{\mathrm{k}} \xi$ in $\mathrm{A}_{\mathrm{k}} \quad(\mathrm{k}=1,2)$.

Proof: If $\left\{\xi_{\alpha}\right\}$ converges to the bicomplex point $\xi$, it is eventually in every neighbourhood of $\xi$ with respect to the idempotent product topology.

Note that $\pi_{\mathrm{k}}\left(\xi_{\alpha}\right)=\left\{{ }^{\mathrm{k}} \xi_{\alpha}\right\}$ and the projections $\pi_{\mathrm{k}}: \mathrm{A}_{1} \times_{\mathrm{e}} \mathrm{A}_{2} \rightarrow \mathrm{A}_{\mathrm{k}}$ are continuous, $\mathrm{k}=1$, 2. (cf. [5]).

Therefore, the net $\left\{{ }^{k} \xi_{\alpha}\right\}$ in $A_{k}$ is eventually in every neighbourhood of $\pi_{\mathrm{k}}(\xi), \mathrm{k}=1,2$.

Hence the net $\left\{{ }^{k} \xi_{\alpha}\right\}$ in $A_{k}$ is confined to ${ }^{k} \xi$ in $\mathrm{A}_{\mathrm{k}}, \mathrm{k}=1,2$.

The converse is straightforward.

\subsection{Note}

The analogue of the above result is not true for any type of ID - confinement (except ID - Point confinement) of the bicomplex nets with respect to the idempotent order topology on $\mathrm{C}_{2}$. Further, there is a characteristic difference between the convergence in the idempotent product topology and the confinement in the idempotent order topology in the sense that for any type of confinement (except ID Point confinement) of a bicomplex net with respect to the idempotent order topology it is not necessary to have all the component nets to be convergent. We prove the following results in this context.

\subsection{Theorem}

If the bicomplex net $\left\{\xi_{\alpha}\right\}$ is ID - F confined to the ID frame $\left(\operatorname{Re}^{1} \xi=a\right)$, the projection net $\left\{{ }^{1} \xi_{\alpha}\right\}$ in $A_{1}$ is confined to the line $\mathrm{x}=\mathrm{a}$ in $\mathrm{A}_{1}$.

Proof: Suppose that the bicomplex net $\left\{\xi_{\alpha}\right\}$ defined by (4.2), is ID - F confined to the ID - frame $\left(\operatorname{Re}^{1} \xi=a\right)$.

Therefore the bicomplex net $\left\{\xi_{\alpha}\right\}$ is eventually in every member of the family $\mathrm{N}_{1}$ (of open ID - space segments) containing the ID - frame $\left(\operatorname{Re}^{1} \xi=\mathrm{a}\right)$.

Now, the projection of every member of $\mathrm{N}_{1}$ on $\mathrm{A}_{1}$ is a plane segment in $A_{1}$ and therefore is a basis element of the dictionary order topology on $A_{1}$. Hence, the projection net $\left\{{ }^{1} \xi_{\alpha}\right\}$ is eventually in every basis element of the dictionary order topology on $\mathrm{A}_{1}$ containing the line segment $\mathrm{x}=\mathrm{a}$ in $\mathrm{A}_{1}$.

Hence the net $\left\{{ }^{1} \xi_{\alpha}\right\}$ is confined to the line segment $\mathrm{x}=\mathrm{a}$ in $\mathrm{A}_{1}$.

\subsection{Theorem}

If the bicomplex net $\left\{\xi_{\alpha}\right\}$ is ID - P confined to the ID plane $\left(\operatorname{Re}^{1}{ }^{1} \xi=\mathrm{a}, \operatorname{Im}{ }^{1} \xi=\mathrm{b}\right)$, the projection net $\left\{{ }^{1} \xi_{\alpha}\right\}$ is confined to the point $a+i_{1} b$ in $A_{1}$.

Proof: Suppose that the bicomplex net $\left\{\xi_{\alpha}\right\}$ defined by (4.2), is ID - $\mathrm{P}$ confined to the ID - plane $\left(\operatorname{Re}^{1} \xi=a, \operatorname{Im}^{1} \xi=b\right)$. 
Therefore, the bicomplex net $\left\{\xi_{\alpha}\right\}$ is eventually in every member of the family $\mathrm{N}_{2}$ (of open ID - frame segments) containing the ID - plane $\left(\operatorname{Re}^{1} \xi=\mathrm{a}, \operatorname{Im}{ }^{1} \xi=\mathrm{b}\right)$.

Note that the projection of every member of $\mathrm{N}_{2}$ on the auxiliary space $A_{1}$ is a basis element (in fact, an open interval) of the dictionary order topology on $A_{1}$ containing the point $a+i_{1} b$.

So the projection net $\left\{{ }^{1} \xi_{\alpha}\right\}$ is eventually in every basis element of dictionary order topology on the auxiliary complex space $A_{1}$ containing the point $a+i_{1} b$.

Therefore, the projection net $\left\{{ }^{1} \xi_{\alpha}\right\}$ is confined to the point $a+i_{1} b$ in $A_{1}$.

\subsection{Theorem}

If the bicomplex net $\left\{\xi_{\alpha}\right\}$ is ID - L confined to the ID - line $\left(\operatorname{Re}^{1} \xi=\mathrm{a}, \operatorname{Im}^{1}{ }^{1} \xi=\mathrm{b}, \operatorname{Re}^{2} \xi=\mathrm{c}\right)$, the projection net $\left\{{ }^{1} \xi_{\alpha}\right\}$ converges to the point $a+i_{1} b$ in $A_{1}$ and the projection net $\left\{{ }^{2} \xi_{\alpha}\right\}$ is confined to the line $\mathrm{x}=\mathrm{c}$ in $\mathrm{A}_{2}$.

Proof: Let the bicomplex net $\left\{\xi_{\alpha}\right\}$ defined by (4.2), be ID - $\mathrm{L}$ confined to the ID - line

$$
\left(\operatorname{Re}^{1} \xi=\mathrm{a}, \operatorname{Im}^{1} \xi=\mathrm{b}, \operatorname{Re}^{2} \xi=\mathrm{c}\right) .
$$

Therefore, the bicomplex net $\left\{\xi_{\alpha}\right\}$ is eventually in every member of the family $\mathrm{N}_{3}$ (of open ID - plane segments) containing the ID - line

$$
\left(\operatorname{Re}^{1} \xi=\mathrm{a}, \operatorname{Im}^{1} \xi=\mathrm{b}, \operatorname{Re}^{2} \xi=\mathrm{c}\right) .
$$

Since the projection of every member of $\mathrm{N}_{3}$ on $\mathrm{A}_{1}$ is a point $a+i_{1} b$.

Therefore, the projection net $\left\{{ }^{1} \xi_{\alpha}\right\}$ in $A_{1}$ is eventually static on $a+i_{1} b$ in $A_{1}$, so it is convergent to the point $a+i_{1} b$ in $A_{1}$.

The projection on $A_{2}$ of every member of $\mathrm{N}_{3}$ (of open ID - plane segments) is a plane segment in $A_{2}$, which is a basis element of the dictionary order topology on $A_{2}$.

Therefore, the projection net $\left\{{ }^{2} \xi_{\alpha}\right\}$ in $A_{2}$ is eventually in every basis element of the dictionary order topology on $\mathrm{A}_{2}$ containing the line $\mathrm{x}=\mathrm{c}$ in $\mathrm{A}_{2}$.

Hence, the projection net $\left\{{ }^{2} \xi_{\alpha}\right\}$ in $A_{2}$ is confined to the line $\mathrm{x}=\mathrm{c}$ in $\mathrm{A}_{2}$.

\subsection{Theorem}

If the bicomplex net $\left\{\xi_{\alpha}\right\}$ is ID - Point confined to the bicomplex point $\left(a+i_{1} b\right) e_{1}+\left(c+i_{1} d\right) e_{2}$, the projection net $\left\{{ }^{1} \xi_{\alpha}\right\}$ in $\mathrm{A}_{1}$ converge to the point $\mathrm{a}+\mathrm{i}_{1} \mathrm{~b}$ in $\mathrm{A}_{1}$ and the projection net $\left\{{ }^{2} \xi_{\alpha}\right\}$ in $A_{2}$ converge to the point $\mathrm{c}+\mathrm{i}_{1} \mathrm{~d}$ in $\mathrm{A}_{2}$.

Proof: Let the bicomplex net $\left\{\xi_{\alpha}\right\}$ defined by (4.2), be ID - Point confined to the bicomplex point $\left(a+i_{1} b\right) e_{1}+\left(c+i_{1} d\right) e_{2}$.

Therefore, it is eventually in every member of the family $\mathrm{N}_{4}$ (of open ID - line segments) containing the point $\left(a+i_{1} b\right) e_{1}+\left(c+i_{1} d\right) e_{2}$. So that the projection net $\left\{{ }^{1} \xi_{\alpha}\right\}$ in $A_{1}$ is confined to the point $a+i_{1} b$ in $A_{1}$ and the projection net $\left\{{ }^{2} \xi_{\alpha}\right\}$ in $A_{2}$ is confined to the point $c+i_{1} d$ in $A_{2}$.

\subsection{Example}

Consider the bicomplex net $\left\{\xi_{\alpha}\right\}$ of Example 4.11.

The net $\left\{\operatorname{Re}^{1} \xi_{\alpha}\right\}$ converges to $2 \mathrm{a}$ and the net $\left\{\operatorname{Im}{ }^{1} \xi_{\alpha}\right\}$ converges to $2 \mathrm{a}$. However, the nets $\left\{\operatorname{Re}^{2} \xi_{\alpha}\right\}$ and $\left\{\operatorname{Im}^{2} \xi_{\alpha}\right\}$ are not convergent and hence the projection net $\left\{{ }^{2} \xi_{\alpha}\right\}$ in $\mathrm{A}_{2}$ is not confined in $\mathrm{A}_{2}$. So the bicomplex net $\left\{\xi_{\alpha}\right\}$ does not converge in the idempotent product topology.

But the projection net $\left\{{ }^{1} \xi_{\alpha}\right\}$ in $A_{1}$ is confined to the point $2 a+i_{1} 2 a$ in $A_{2}$. Hence the bicomplex net is ID $\mathrm{P}$ confined to the ID - plane $\left(\operatorname{Re}^{1} \xi=2 \mathrm{a}, \operatorname{Im}{ }^{1} \xi=2 \mathrm{a}\right)$.

\subsection{Example}

Consider the directed net $\left(\mathrm{Q}^{+}, \geq\right)$. Define a bicomplex net $\left\{\xi_{\alpha}\right\}$ as follows:

$$
\left\{\xi_{\alpha}\right\}=\left\{\begin{array}{c}
\left(a-k_{\alpha}\right)+i_{1}\left(b-h_{\alpha}+1 / \alpha\right) \\
+i_{2}\left(-b+h_{\alpha}+1 / \alpha\right)+i_{1} i_{2} k_{\alpha}
\end{array}\right\} \forall \alpha \in Q^{+},
$$

$\left\{\mathrm{h}_{\alpha}\right\}$ and $\left\{\mathrm{k}_{\alpha}\right\}$ being eventually static on 0 .

The projection net $\left\{{ }^{1} \xi_{\alpha}\right\}$ in $A_{1}$ is confined to the point $a+i_{1} 2 b$ in $A_{1}$ and the projection net $\left\{{ }^{2} \xi_{\alpha}\right\}$ in $A_{2}$ is confined to the point $a+i_{1} 0$ in $A_{2}$. Therefore, the bicomplex net is ID - Point confined to the point $\left(a+i_{1} 2 b\right) e_{1}+\left(a+i_{1} 0\right) e_{2}$.

Since, all the component nets are convergent. Therefore, the bicomplex net converges to the point $\left(a+i_{1} 2 b\right) e_{1}+\left(a+i_{1} 0\right) e_{2}$ in the classical sense.

\section{REFERENCES}

[1] Price, G. B., 'An introduction to multicomplex spaces and functions', Marcel Dekker Inc., New York, (1991)

[2] Srivastava, Rajiv K., 'Bicomplex numbers: analysis and applications', Math. Student, 72 (1-4) (2003), 63 - 87

[3] Srivastava, Rajiv K., Certain topological aspects of bicomplex space', Bull. Pure \& Appl. Math., 2 (2008), 222 - 234 
[4] Srivastava, Rajiv K. \& Singh, Sukhdev, 'Certain bicomplex dictionary order topologies', International J. of Math. Sci. \& Engg. Appls. (4), III (2010), 245 - 258

[5] Srivastava, Rajiv K., 'Meromorphic Functions of a Bicomplex Variable', International Conference of Special Functions and their Applications, (2011)
[6] Srivastava, Rajiv K., 'On the modified consistency in the bicomplex algebra', Symposium 'Analysis: Some Recent Facets' $98^{\text {th }}$ Indian Science Congress, (2011)

[7] Willard, S., 'General topology', Addison Wesley Massachusetts, (1970) 